\title{
Public Health Policy in Support of Insurance Coverage for Smoking Cessation Treatments
}

\section{Politique de santé publique en faveur de la couverture d'assurance pour les traitements visant à mettre fin au tabagisme}

\author{
(3) \\ ROBERT SCHWARTZ, PHD \\ Ontario Tobacco Research Unit, Dalla Lana School of Public Health \\ Centre for Addictions and Mental Health, University of Toronto \\ Toronto, ON \\ FARZANA HAJI, MA \\ Ontario Tobacco Research Unit, Dalla Lana School of Public Health \\ University of Toronto \\ Toronto, ON \\ ALEXEY BABAYAN, PHD \\ Ontario Tobacco Research Unit, Dalla Lana School of Public Health \\ University of Toronto \\ Toronto, ON \\ CHRISTOPHER LONGO, PHD \\ DeGroote School of Business, McMaster University \\ Hamilton, $\mathrm{ON}$ \\ ROBERTA FERRENCE, PHD \\ Ontario Tobacco Research Unit, Dalla Lana School of Public Health \\ University of Toronto \\ Toronto, ON
}

\begin{abstract}
Insurance coverage for evidence-based smoking cessation treatments (SCTs) promotes uptake and reduces smoking rates. Published studies in this area are based in the US where employers are the primary source of health insurance. In Ontario, Canada, publicly funded
\end{abstract}


healthcare does not cover SCTs, but it can be supplemented with employer-sponsored benefit plans. This study explores factors affecting the inclusion/exclusion of smoking cessation (SC) benefits. In total, 17 interviews were conducted with eight employers (auto, retail, banking, municipal and university industries), four health insurers, two government representatives and three advisors/consultants. Overall, SCT coverage varied among industries; it was inconsistently restrictive and SCT differed by coverage amount and length of use. Barriers impeding coverage included the lack of the following: Canadian-specific return on investment (ROI), SC cost information, employer demand, government regulations/incentives and employee awareness of and demand. A Canadian evidence-based calculation of ROI for SC coupled with government incentives and public education may be needed to promote uptake of SCT coverage by employers.

\section{Résumé}

La couverture d'assurance pour les traitements fondés sur les données probantes et visant la désaccoutumance du tabac (TDT) favorise l'adhésion et aide à réduire le taux de tabagisme. Les études publiées sur ce sujet concernent les États-Unis, où les employeurs constituent la première source d'assurance maladie. En Ontario, Canada, les services publics de santé ne couvrent pas les TDT, mais peuvent être suppléés par des régimes d'avantages sociaux parrainés par les employeurs. Cette étude examine les facteurs qui affectent l'inclusion ou l'exclusion à ces avantages sociaux. En tout, 17 entrevues ont été menées auprès de huit employeurs (automobile, vente au détail, banque, municipal et universitaire), quatre assureurs, deux représentants gouvernementaux et trois consultants. Dans l'ensemble, la couverture des TDT varie selon les industries; elle était restrictive de façon variable et le montant de la couverture ainsi que la durée des TDT différaient. Les obstacles à la couverture comprennent des lacunes quant aux éléments suivants : rendement du capital investi (RCI) spécifique au Canada, renseignements sur les coûts pour la désaccoutumance du tabac, demande de la part des employeurs, réglementations et incitatifs gouvernementaux, sensibilisation des employés et demande de leur part. Un calcul du RCI fondé sur les données probantes au Canada pour la désaccoutumance du tabac conjugué à des incitatifs gouvernementaux et à l'éducation du publique serait sans doute nécessaire pour promouvoir l'adhésion des employeurs à une couverture pour les TDT.

I N TOTAL, I $8 \%$ OF ONTARIANS (AgED $\geq$ I 2 YeARS) ARE SMOKERS, REPRESENTING AN estimated 2.4 million people. Smoking remains the leading cause of preventable mortality and morbidity resulting in 13,000 deaths and almost $\$ 7.7$ billion in direct healthcare expenditures and lost productivity every year in Ontario alone (OAHPP 2010). The Conference Board of Canada (2006) estimates that every employee who smokes can cost an employer up to $\$ 3,396$ a year through increased absenteeism, decreased productivity and the costs associated with maintaining and cleaning outside smoking areas. 
In 2000, the US Public Health Service Guidelines recognized smoking cessation treatments (SCTs) as cost-effective and clinically sound. SCTs can double or triple the likelihood of quitting smoking compared with quitting without such treatment (Fiore et al. 2000; McGoldrick and Boonn 2010; Penz et al. 2010).

In Canada, eight provinces and territories provide some SCT coverage, whereas four do not (Madore and Tiedemann 2005). Ontario, Canada's largest province by population, is positioned in the middle, providing only prescription coverage for those who are unemployed, have a disability or are aged $>65$ years through the Ontario Drug Benefit (ODB) program. There is limited knowledge about the extent of SCT coverage by Ontario employers. One study suggests that with the introduction of the Smoke-Free Ontario Act (SFOA) in 2006, many private Ontario-based drug plans began to offer smoking cessation (SC) benefits as an option for employers under an increasing demand for wellness initiatives (Jackson et al. 2008). These plans tend to include pharmacotherapy, while nicotine replacement therapy (NRT) is excluded, as it is considered an over-the-counter product (Jackson et al. 2008). However, little is known about the factors that facilitate and/or prevent adoption of SCT coverage under employer-sponsored plans. We chose to study Ontario because many head offices of larger private sector employers in Canada are based in Ontario, and because the public sector employers in Ontario tend to be larger than those in other provinces.

Although no published Canadian or Ontarian research on the use and effectiveness of employer-sponsored SCT insurance coverage is available, several American studies have found employer-sponsored SCT insurance coverage to be effective. As employed Ontarian smokers do not receive SCT coverage from the government health insurance plan, it might be expected that employer-provided supplementary insurance would be an effective tool as it is in the US. In comparing the two countries, it is important to note that although employers are the primary source of health coverage in the US (Juba et al. 1980; Kaper et al. 2005), the government provides insurance coverage for hospital, physician and certain other services in Canada, with some variation in the extent of coverage among provinces and territories. In Ontario, specifically, employer-sponsored benefits tend to complement what already exists through the public health insurance system. This may reduce incentives for employers in Canada to provide SCT insurance coverage, compared to the US.

Research indicates that insurance coverage for evidence-based SCTs such as pharmacotherapy, NRT and behavioural counselling, promotes uptake and reduces smoking rates (Curry et al. 1998; Schauffler 1997; US Department of Health and Human Services 2012). American guidelines recommend a comprehensive tobacco strategy, including counselling, alongside pharmacotherapy treatments for SC within an employer-sponsored, workplace health insurance plan (US Department of Health and Human Services 2009). Access to evidence-based SCTs is likely to reduce employer and healthcare expenditures (Mulligan 2010). Several studies suggest that effects are maximized when SCT coverage is part of a comprehensive approach to SC in the workplace (Au-Yeung et al. 2010; Javitz et al. 2006; Mulligan 2010). 
Coverage for SCTs amongst American employers varies despite reports indicating its positive effects on productivity, absenteeism and presenteesim (Barbeau et al. 2001; Harris et al. 2001; Johns 2009). Au-Yeung et al. (2010) identify the following factors that influence employers' decisions regarding health insurance coverage: cost to the employer, utilization/ demand within the company, health of employees, evidence of benefit effectiveness and recommendations from advisors. Recent amendments to the Affordable Care Act provided for substantial coverage of cessation (see http://www.lung.org/our-initiatives/tobacco/cessationand-prevention/tobacco-cessation-treatment-what-is-covered.html).

The objectives of the current study included the following: (1) to explore the extent of coverage of SCTs among employers in various sectors in Ontario (auto, retail, banking, universities, municipal government); (2) to identify the main factors that influence decisions relating to purchasing and modifying health benefit coverage, including SCT; and (3) to examine the barriers to implementing and/or expanding insurance coverage for SCTs from the perspective of Ontario health insurers, employers, advisors/consultants and regulatory/government representatives.

\section{Methods}

\section{Study design and recruitment}

This exploratory study applied a qualitative research approach to gain an understanding of the current state of SCT coverage under employer-sponsored health plans. Semi-structured interviews were conducted with 18 key informants, including the following: eight employers, four health insurers, three advisors/consultants who provide services to employers and unions and three government representatives. In addition, relevant documents obtained from interviewees were reviewed (benefit plans, organizational guidelines for health insurance).

Data collection took place between May and December 2012. Representatives of the employers were often benefit specialists, directors of pension and benefits, HR specialists and individuals from the finance department. In some instances, two individuals from an organization participated in the interviews to provide further insight into the benefit negotiation and selection process. Because of recruitment challenges, no employer was selected from the auto industry.

Ethics approval was obtained from the University of Toronto's Research Ethics Board on May 15, 2012. The participants were provided with letters of information explaining the purpose of the study, the aim of the interviews and an outline addressing confidentiality and consent concerns.

Interview guides were developed for each group of key informants and their perspectives regarding factors influencing the purchase of benefits, the provision of health benefits, including SCTs, and the benefits negotiation process were examined. Individuals were also asked to discuss facilitators and barriers in this process (see Appendix 1 for interview guides, available at: http://www.longwoods.com/content/25098).

Interviews were conducted over the phone and lasted between 30 minutes and 1 hour. Written and/or oral consent was obtained from each interview participant before commencing the interview. Telephone interviews were digitally recorded, transcribed and then 
analyzed using the qualitative data analysis software NVivo 9.2. The data were organized into categories based on responses to questions and emerging themes across interviews. Broader categories or themes were assigned a "node" and subthemes were identified and coded under these heading nodes. A series of attributes was created for each respondent to allow for analysis according to the following key characteristics: occupation (health insurer, government representative, employer, and advisor) and type of employer (car manufacturing, retail, university, municipality and banking), as well as whether an organization provided SCT benefits.

As limited study funding did not enable ensuring representativeness of industries, we sought to purposefully select information-rich case studies of companies/organizations referred to here as employers. The study aimed to select employers within five various sectors/industries chosen to include public and private, white and blue collar, large and small, high or low turnover rates and both unionized and non-unionized employees - as unions often play a role in negotiating insurance benefits packages: retail trade, car manufacturing, banking, universities and municipal government. Criteria that guided selection of employers from each industry included the following: type of employers (public or private), type of employee (white or blue collar), size of employer (large [>500 employees] or small) and level of turnover (high or low). To provide a systematic approach to the recruitment of employers, a matrix was created with the aforementioned attributes and was used to assist in this process. We aimed to select two employers from each industry/sector and interview two key informants from each organization.

Three Ontario municipalities of varying sizes were examined in this study: two large urban centres ( $>100,000$ people) and one small community ( $<100,000$ people). Employees in all municipalities were represented by several unions. One of the larger municipalities had a segment of their employees that were non-unionized. Two universities were selected, both with several unions embedded within their organizations. Only one retail establishment was recruited into the study. The company had approximately 30,000 employees throughout Canada and is recognized across the world. The organization's employees were not unionized. Because of recruitment challenges, no employer was selected from the auto industry. One bank was recruited for the study. The bank has 36,000 active employees and 8,000 retirees across Canada.

\section{Results}

\section{SCT coverage}

In our sample, coverage for SCTs varied greatly. The coverage was typically restricted in terms of the type of SCTs insured (e.g., prescription-only, NRT-only etc.), annual or lifetime monetary amount and length of use (Table 1).

Cessation counselling was available in most organizations through employee assistance programs (EAPs). Insurance coverage is generally focused on pharmacotherapy and sometimes also includes psychosocial counselling. 
Public Health Policy in Support of Insurance Coverage for Smoking Cessation Treatments

TABLE 1. Summary of SCT coverage by employers who participated in the study

\begin{tabular}{|l|l|}
\hline \multicolumn{2}{|l|}{ Employer/industry } \\
\hline Municipal government & One-time-only \$300 incentive for any SCT \\
\hline Municipality (small) & Pharmacotherapies only \\
\hline Municipality (large) & \$400 one-time amount for prescription medication, excluding bupropion \\
\hline Municipality (large) & No coverage, provides EAP \\
\hline University & Pharmacotherapies only - NRT recently excluded, EAP offered \\
\hline University (large) & \multicolumn{2}{|l}{} \\
\hline University (small) & \$300/year on any SCT, eight nurse-assisted sessions, EAP offered \\
\hline Retail & \multicolumn{2}{|l}{} \\
\hline Retail (large) & Could not provide detailed description of the benefits, EAP offered \\
\hline Banking &
\end{tabular}

EAP = employee assistance program; NRT = nicotine replacement therapy; SCT $=$ smoking cessation treatment.

One university did not provide any coverage for SCTs. The human resources benefits' specialist explained that smoking is a rare occurrence on campus because of the anti-smoking bylaws. Key informants from both universities sensed that they had a low percentage of smokers and pointed to the lack of employee demand for SCT coverage. Neither offered a wellness program to their employees and cited cost as a significant factor.

The retail organization provided $\$ 300$ per year for an employee to use on any SCTs, such as NRT, prescription medication or behavioural counselling. The latter could also be provided through the EAP. In addition, employees could access eight nurse-assisted sessions annually to get SC information and counselling.

Factors affecting employers' decisions about the coverage of health benefits

Key informant interviews revealed that a number of factors affect decisions on health benefit selection and modification including benefit cost, cost of related conditions (return on investment, absenteeism, etc.), expert support from an advisor, and employee and employer demand.

\section{$\operatorname{COST}$}

A majority of employers, representatives of health insurance companies, government officials and advisors agreed that cost is the number one factor that influences insurance plan selection. One health insurance representative noted that cost has become an increasingly important factor within the past 5-10 years:

"... so what we did see like 2008 when the economy melted down, we did see a lot of people that were looking for ways to save money or, or they had, they had to or they were potentially going to have to go out of business ... that included the, 
the benefit program too so they, they'd be either get rid of things like OTCs (overthe-counters) or increase the cost sharing so if you had like it didn't cost the plan member anything for a prescription before maybe now they're going to be looking at having to pay five bucks a prescription." - Health insurer

In the same vein, an employer representing the municipal government explained that because of a substantial increase in healthcare cost in the past 5-10 years, it has become difficult to offer insurance plans similar to those used in prior years. He/she explained:

“... you know roll back a little bit you know because it's become so expensive. I mean even ten years ago drugs weren't nearly the cost of what they are now and most employers are facing like ten percent increases in their benefit costs over the years. That's crazy." - Employer [municipality]

Two employers representing the university/education sector also noted that costs have continually increased over the past 5-10 years. One employer commented that universities have been forced to become creative in regards to cost-cutting measures.

"I know it's cost, it all came down to cost. It always does ... Universities on the whole and we're no exception are really pressed for cash so we try to look for things that are not, don't take a lot of money but that's very difficult to find things that have great value that don't cost anything" - Employer [university]

All advisors/consultants who participated in interviews agreed with the perspectives of both health insurance companies and employers. They confirmed that discovering the lowest-cost health insurance plan is the top priority for the employers.

\section{RETURN ON INVESTMENT}

The ROI was chosen by all key informants as the second most important factor when purchasing health insurance packages. Providing employees with an EAP, gym memberships, dietary consultations and access to "lunch and learns" were perceived by key informants as potential avenues to reduce absenteeism and medical costs paid through supplementary health insurance, thus providing a return on the investment made. These services are usually discussed with employers as part of a wellness package. As explained by health insurers, wellness benefits are considered for inclusion in a health insurance package if an employer is interested in reducing all costs of related conditions, such as absenteeism and presenteeism, while increasing productivity and employee satisfaction. Because smoking is considered a lifestyle choice, it is typically placed within a wellness package. Along with pension and benefit costs, both universities considered the cost of related conditions (absenteeism and presenteeism) and employee demand to be important during the collective bargaining process. 
Public Health Policy in Support of Insurance Coverage for Smoking Cessation Treatments

Several health insurance representatives mentioned that it is often difficult to quantify the social and economic benefits for covering SCTs for Canadian employers. One health insurer explained:

"Yeah it's, it's a bit of a different scenario in Canada where and, and we see this a lot of stuff for all kinds of different interventions right, where much, whenever much of your return is based on reduced hospital and medical spend and physician visits and hospitalizations and things like that [in the US], you see a you get that, you build that, get that return back really, really quickly in the US where it's the employer that's paying for all that but it, it's a whole, it's a different picture in Canada." - Health insurer

Health insurance companies have particularly struggled with proposing wellness packages, including SCTs, to employers because of difficulties in quantifying the ROI. One health insurance representative explained that although many employers strive to acquire high ROIs on their investments, wellness packages are substantially different from other benefits. He/she explained that the philosophy of a healthy workforce has not yet been grasped by employers:

"Wellness programs have generally struggled somewhat in gaining traction with employers from the standpoint that up until recently, it's been hard to quantify some of the savings... Yeah, yeah so you know that's been a challenge. I think more employers are coming around to the idea that keeping the workforce healthy and productive upfront is a better investment than trying to take care of them once they're already sick and I mean that's an across the board thing. That's our healthcare system today is built around that and you know we see some movement on the benefit plan side but it's a slow evolution. It's not a wholesale change... it's again a matter of quantifying the savings, quantifying the benefit ..." - Health insurer

Interviews with employers also highlighted the importance of ROI from a wellness benefits viewpoint. While all employers discussed the importance of the costs of smoking in the forms of absenteeism, presenteeism and low productivity, as an essential factor that determines the scope of health insurance plans, they mentioned that the health benefits were not currently contextualized in that manner. Many employers felt that these costs would increase in importance in the near future, once health insurers and/or advisors would be able to provide further ROI information in regards to wellness benefits.

One employer representing the university/education sector admitted that the idea of preventative measures in the workplace is somewhat new; however, the university is willing to invest in wellness initiatives to reduce the cost of absenteeism in the future.

".. you know for us we also look at the cost related to the condition to the company so we're starting to get more into looking at things like absenteeism in our sick leave 
management side and where we're seeing conditions that are preventable you know we do want to direct some money towards anything of that nature." - Employer [university]

\section{EXPERT SUPPORT FROM ADVISORS}

Health insurers and employers agree that the guidance provided by an advisor is essential for the design of a health insurance plan. One health insurer explained that advisors facilitate the selection of health benefits by engaging in negotiations with health insurers on behalf of employers.

During the interviews, advisors shared examples of how their knowledge and expertise informed employers' decisions about selecting coverage for SCTs. Based on the scientific evidence that SC support from physicians can increase successful quitting, one advisor suggested that the employer provide coverage for prescription medication only. This would force an employee to visit a physician to receive a prescription and cessation advice. Another advisor communicated the importance of wellness programs to their employer in addition to the SCTs, based on findings from the literature. As a result, the addition of wellness benefits occurred through an insurance contract amendment.

\section{EMPLOYEE DEMAND}

Employee demand for coverage emerged as an essential factor that influences health insurance benefit selection and modification. This held true for organizations with and without unionized employees.

A key informant from a large retail company without union representation mentioned that employee demand was the most influential factor for their organization. This company had a strong organizational philosophy with respect to employee wellness and satisfaction. Although cost is always a concern within any organization, the key informant explained that in comparison to their US-based retail stores, Canadian health benefits are $50 \%$ less costly per payroll, and the company would prefer to increase employee satisfaction and wellness of their employees in any way possible.

"Employee demand, definitely [is the number one factor] ... like I said we're fortunate as a company that we've been very successful in the past and we for all kinds of reasons, have kept our healthcare costs in check ..." - Employer [retail]

\section{EMPLOYER DEMAND}

Health insurers indicated in interviews that employers rarely ask for SCT coverage to be included in benefits packages. Their perception is that employers have not generally made the connection between SCT coverage and its potential role in decreasing problems such as absenteeism and presenteeism.

Again, I would start with what are they [employers] trying to achieve overall as an objective of their group benefits program, what are their needs you know and we 
talked a little bit about that, what challenges are they facing so other than the core benefits they could have specific challenges in the workplace. Maybe they're really struggling with absenteeism, maybe their disability, the experience there is you know it's just getting to the point where they need to do something. That employer has specific needs so they need to talk to carriers and find out what they can do to help so that would also be part of it. - Health insurer

\section{Barriers to adopting and using SCTs}

\section{LACK OF CANADA-SPECIFIC ROI WITH REGARDS TO SCTs}

Interviews with advisors reveal that even if employers are interested in providing coverage for SCTs and are looking for innovative ways to contain future benefit costs without having to scale back on the scope of the benefits, the challenge has been to demonstrate the potential ROI. Advisors explained that most companies intuitively know that providing SCTs will be profitable to their organization, but they often lose interest in the benefit when they are required to justify its cost to their human resources department. They agreed that limited knowledge of the ROI on SCTs in a Canadian context is a major issue, and further information is required to make employers adopt SCT benefits. The need for Canada-specific ROI analysis stems from the different roles of government in paying for general healthcare costs. In the US, employers also pay for healthcare, so the cost argument looks quite different from that in Canada where the employer does not bear the healthcare costs related to long-term smoking.

Key informants from health insurance companies also pointed to the lack of a Canadaspecific ROI on SCTs. They added that Ontario-based studies are needed to examine the use and effects of SCTs by employees and estimate ROI on SCTs. Without this information, it has become difficult for health insurers to persuade employers to purchase an additional benefit for their employee benefit plans.

\section{LACK OF INFORMATION WITH REGARD TO COST FOR SCTS}

Surprisingly, in that cost is considered a major factor influencing employers' decisions about the design and scope of benefits plan, lack of information about the specific costs of SCT benefits was regarded as a barrier by many employers. Health insurers and advisors explained that SCTs are often grouped with other wellness benefits, as it is still difficult to quantify the cost of an SC benefit. No advisor, health insurer or employer was able to elaborate on the cost of a SC benefit.

\section{LACK OF EMPLOYER DEMAND FOR SCTs}

Two health insurers explained that, to date, they have not had many requests for the addition of SCTs from employers/advisors. However, both insurers assured that if SCTs were requested, it would not be difficult to amend current benefit contracts. One insurer commented:

"We'll include it [smoking cessation services] when we hear it, absolutely ... You know what, nobody's ever asked for it." - Health insurer 


\section{LACK OF EMPLOYEE AWARENESS OF AND DEMAND FOR SCTS}

Employers without SCT coverage pointed to the lack of demand for cessation products and services as a barrier to insuring SCTs. In particular, a unionized employer indicated that there had not been any discussion regarding SCTs during collective bargaining agreements for the past 15 years.

Employers that reported offering SCTs highlighted the lack of employee awareness of SCT coverage as a barrier. Three employers explained that their employees often do not know if SCTs are covered under the benefit plans and the extent of the coverage. Consequently, utilization of cessation services is often low.

\section{LACK OF GOVERNMENT ASSISTANCE OR INCENTIVES}

Employers, both with and without SCT coverage, highlighted lack of government assistance and incentives as barriers to insuring SCTs for their employees. However, they differ in their opinion about the extent of the government responsibility on this issue. Employers with current SCT coverage indicated that coverage of SCT should be a shared responsibility between employers and the government of Ontario, as benefits accrued in the future would benefit the government and the general public. One employer suggested a tax incentive for Ontario employers to provide various forms of SC support to their employees (i.e., health benefit, "lunch and learns" and information sessions). In contrast, employers without SCT coverage felt that the government should take full responsibility for providing SCTs to employees and the general public.

\section{Discussion}

The study identified a number of factors that influence the process of selecting health benefits, including SCTs. Consistent with other studies, the cost of benefits carried the greatest weight, followed by ROI considerations, expert support from an advisor and employee demand (Au-Yeung et al. 2010). Interestingly, it is less clear what employers understand about the relative costs and benefits of SCT coverage. This could be limited to the opportunity cost of using those funds for other benefits, it could include the impact on absenteeism and presenteeism, the potential reduction in medications for related illnesses or the impact on publicly funded healthcare system. Evidence from these interviews suggest that the narrowest definition of costs is most often assumed and may account for the lack of confidence in the net benefit of SCTs. The importance of organizational culture supporting the health and wellness of employees was also highlighted as an important factor.

A number of barriers to inclusion and expansion of SCTs in employment-based health benefit plans emerged. Lack of Canada-specific ROI analyses with regards to SCTs were highlighted as a major issue by employers, insurers and advisors alike. ROI analysis for jurisdictions where general healthcare costs are covered through employer insurance plans is not applicable to the Canadian context where these costs are borne by the government. Interviewees indicated a strong need for evidence-based and Canada-specific quantitative data to inform decisions about the inclusion of SCT under employment-based health benefit plans. 
This study provides insight into the characteristics of SCT coverage by Ontario employers in various industries. Although most employers examined in this study offer SCTs to their employees, the insurance coverage varies greatly across the employers and is typically restricted in terms of cessation services and medications, annual or lifetime monetary amount and length of use.

These restrictions limit employees' opportunities and strategies to make quit attempts and maintain abstinence. Comprehensive cessation strategies, with no extra financial cost to the employee, telephone counselling, on-site group programs, community group programs and effective internal marketing of SCTs available through the health benefit plan would assist in enhancing the effectiveness of SCT coverage (Au-Yeung et al. 2010; Javitz et al. 2006; Mulligan 2010).

An unexpected finding is that the uptake of SCT benefits appears to be low, as employees are reported by employers to have little or no knowledge of the existence of SCTs within their benefit plans. This may, in part, be explained by the lack of effective dissemination strategies tailored to specific categories of employees (indoor vs. outdoor, blue- vs. white-collar workers).

This study has some limitations. One of them is the small convenience sample of study participants. It proved difficult to recruit employers, particularly from the auto industry. Furthermore, researchers found it difficult to recruit employers through HR representatives; therefore, most of the employers were recruited through referrals from other key informants (insurance agents, advisors). Further, although most employers (six out of seven) involved in the study reported providing some coverage of SCTs for their employees, this finding cannot be generalized to represent the current state of coverage of SCTs within and across various industries. Additionally, only two government representatives were able to be reached, where both preferred not to be audio-recorded or share in-depth information. Thus, the results may be of limited generalizability and should be interpreted with caution. In addition, only one person analyzed the interview transcripts. Nevertheless, the study provides insight into Ontario employers' decision-making process regarding the provision of insurance coverage for SCTs and factors influencing their adoption and uptake.

\section{Conclusion}

Findings suggest that there is a role for government to play in encouraging SCT coverage in health benefit plans through tax incentives or direct payment and public education. The ROI is there for government because of the cost offsets that have been proven. Without government support, SCT coverage is unlikely to be taken up in a serious way by most employers. Employer ROI is likely poor because employers do not fully bear the health-related costs of smoking, and because employee awareness and demand is low.

\section{Acknowledgement}

This work was supported by the Canadian Institutes of Health Research, funding reference number 212020 .

Correspondence may be directed to: Robert Schwartz, Ontario Tobacco Research Unit, Dalla Lana School of Public Health, University of Toronto, 155 College Street, 5th floor, Room 530, Toronto, ON M5T 3M7; tel.: 416-978-3901; e-mail: Robert.schwartz@utoronto.ca. 


\section{References}

Au-Yeung, C.M., S.R. Weisman, D.J. Hennrikus, J.L. Forster, R. Skoog, W. Luneburg et al. 2010. “An Evaluation of Health Benefit Modification in Taft-Hartley Health and Welfare Funds - Implications for Encouraging Tobacco-Cessation Coverage." American Journal of Preventative Medicine 39(6S1): S30-S36.

Barbeau, E.M., F. Sorensen, K.M. Conlan, R. Youngstrom and K. Emmons. 2001. "Coverage of Smoking Cessation Treatment by Union Health and Welfare Funds." American Journal of Public Health 91(9): 1412. Conference Board of Canada. 2006. Briefing: Smoking and the Bottom Line: Updating the Costs of Smoking in the Workplace. Retrieved June 2012. <http://www.wechealthunit.org/healthy-living/tobacco/tobaccoreports/006-07\%20Smoking\%20and\%20the\%20Bottom\%20Line-Briefing.pdf >.

Curry, S.J., L.C. Grothaus, T. McAfee and C. Pabiniak. 1998. "Use and Cost Effectiveness of Smoking-Cessation Services under Four Insurance Plans in a Health Maintenance Organization." New England Journal of Medicine 339(10): 673-679.

Fiore, M.C., W.C. Bailey, S.J. Cohen, S.F. Dorman, M.C. Goldstein, E.R. Gritz, et al. 2000. Treating Tobacco Use and Dependence. Clinical Practice Guideline. Rockville, MD: US Department of Health and Human Services.

Harris, J.R., H.H. Schauffler, A. Milstein, P. Powers and D.H. Hopkins. 2001. "Expanding Health Insurance Coverage for Smoking Cessation Treatments: Experience of the Pacific Business Group on Health." American Journal of Health Promotion 15(5): 350-56.

Jackson, M., M. Gaspic-Pickovic and S. Cimino. 2008. “Description of a Canadian Employer-Sponsored Smoking Cessation Program Utilizing Community Pharmacy-Based Cognitive Services." Canadian Pharmacists Journal 141(4).

Javitz, H.S., S.M. Zbikowski, G.E. Swan and L.M. Jack. 2006. "Financial Burden of Tobacco Use: An Employer's Perspective." Clinics in Occupational and Environmental Medicine 5(1): 9-29, vii.

Johns, G. 2009. "Presenteeism in the Workplace: A Review and Research Agenda." Journal of Organizational Behaviour 31(4): 519-42.

Juba, D.A., J.R. Lave and J. Shaddy. 1980. "An Analysis of the Choice of Health Benefit Plans." Inquiry 17: 62-71.

Kaper, J., E.J. Wagena, J.L. Severens and C.P. Van Scayck. 2005. "Healthcare Financing Systems for Increasing the Use of Tobacco Dependence treatment." Cochrane Database System Review (1): CD004305.

Klinkman, M.S. 1991. "The Process of Choice of the Health Plan and Provider: Development of an Integrated Analytic Framework." Medical Care Review 48: 295-330.

Madore, O. and M. Tiedemann. 2005. Private Health Care Funding and Delivery under the Canada Health Act. PRB 05-52E. Ottawa, ON: Parliamentary Information and Research Service, Library of Parliament.

McGoldrick, D.E. and A.V. Boonn. 2010. "Public Policy to Maximize Tobacco Cessation." American Journal of Preventative Medicine 38 (3 Suppl.): S327-32.

Mulligan, P. 2010. “Corporate Smoking Cessation on Long Island." Health Promotion Practice 11(2): $182-87$.

Ontario Agency for Health Protection and Promotion (OAHPP). 2010. Evidence to Guide Action:

Comprehensive Tobacco Control in Ontario. Toronto, ON: Author.

Penz, E.D., B.J. Manns, P.C. Herbert and M.B. Stanbrook. 2010. “Governments, Pay for Smoking Cessation." CMAJ 182(18): E810.

Schauffler, H.H. 1997. "Defining Benefits and Payments for Smoking Cessation Treatments." Tobacco Control 6(Suppl.): S81-S85.

US Department of Health and Human Services. 2012. Healthy People 2010: Understanding and Improving Health (2nd edn). Washington, DC: US Government Printing Office. 